\title{
A Study of Hematological Profile in Dengue Fever in a Tertiary Care Hospital
}

\author{
Supriya Karmakar ${ }^{1}$, Nanda Patil ${ }^{2}$ \\ ${ }^{1}$ Tutor of Pathology, Krishna Institute of Medical Sciences Deemed to be University, Karad. \\ ${ }^{2}$ Professor of Pathology, Krishna Institute of Medical Sciences Deemed to be University, Karad. \\ Corresponding Author: Supriya Karmakar
}

DOI: https://doi.org/10.52403/ijhsr.20220303

\begin{abstract}
Background: Dengue fever and dengue hemorrhagic fever has emerged as a global public health problem in recent decades. ${ }^{(1)}$ It is an acute febrile illness with symptoms of sudden onset of fever, headache, bodyache, generalized weakness, retro-orbital pain and rash. ${ }^{(2)}$ Its diagnosis is based on clinical and laboratory data. Clinical symptoms and signs along with laboratory tests i.e. both nonspecific [blood count, platelet count, prothrombin time (PT)] and specific tests (viral isolation tests and serology for antibody examination) are evaluated for diagnosis. ${ }^{(3,4)}$

Aim: To study haematological profile in patients of dengue fever.

Objective: To correlate haematological parameters with clinical details.

Methods: The present study is a two year hospital based prospective study of all the haematological parameters in patients diagnosed serologically positive as dengue fever in tertiary care centre from June 2019 to May 2021, which includes 210 cases.

Results: 104 cases $(49.5 \%)$ were in the 2 nd decade of life, which was the most common age group. There were $115(54.7 \%)$ males and 95 (45.2\%) females. The most common presenting complaint was fever (185 cases). 98 cases (46.6\%) were noted with hemoglobin ranging from 12-15 gm/dl and with hematocrit levels ranging from 40-49\%. 128 cases $(60.9 \%)$ had TLC within normal limit. Maximum number of patients i.e. 87 cases $(41.4 \%)$ had platelet count with moderate thrombocytopenia. In DHF and DSS cases, $18(72 \%)$ cases showed moderate thrombocytopenia. According to bleeding manifestations, petechiae was noted in 18 cases, hematemesis in 8 cases whereas 3 cases presented with melena.MPV and PDW in thrombocytopenic patients was found to be significantly higher than in non-thrombocytopenic patients.
\end{abstract}

Conclusion: Hematocrit (HCT) and platelet count monitoring is useful to determine therapeutic intervention in case of dengue fever.

Keywords: Dengue fever, haematological profile, clinical correlation.

\section{INTRODUCTION}

Dengue fever and dengue hemorrhagic fever has emerged as a global public health problem in recent decades. ${ }^{(1)}$ In India also dengue fever is an important health problem. ${ }^{(5)}$ Dengue fever is usually an infectious condition caused by an arthropod borne virus. ${ }^{(1)}$

It is an acute febrile illness with symptoms of sudden onset of fever, headache, bodyache, generalized weakness, retro-orbital pain and rash. ${ }^{(2)}$ Its diagnosis is based on clinical and laboratory data. Clinical symptoms and signs along with laboratory tests i.e. both non-specific [blood count, platelet count, prothrombin time (PT) and liver function tests] and specific tests (viral isolation tests and serology for antibody examination) are evaluated for diagnosis. $^{(3,4)}$

The spectrum of dengue infection spreads from an undifferentiated fever and 
dengue fever (DF) to dengue haemorrhagic fever (DHF) with shock and expanded dengue syndrome ${ }^{(6)}$.

The most prominent hematological change is thrombocytopenia and leukopenia. Lymphocytosis is a commonly noted with reactive lymphocytes. There is progressive increase in hematocrit concentration during the progression of dengue fever almost upto $20 \%$ increase from the patient's baseline. ${ }^{(7,8)}$.

DHF and/or DSS are the major cause of mortality lead by multiple reasons for abnormal haemostasis and thrombopahty and coagulation derangements.

Present study was planned to evaluate the hematological profile of the seropositive (IgM, IgG and NS1 antigen) dengue patients admitted in our institute which is a tertiary care centre. ${ }^{(5)}$

This study was done after permission from institutional ethical committee.

OBJECTIVE: To correlate haematological parameters with clinical details.

\section{MATERIALS AND METHODS}

The present study was a two year hospital based prospective study of all the haematological parameters in patients diagnosed serologically positive as dengue fever in tertiary care centre from June 2019 to May 2021, which includes 210 cases. The study was cross sectional, which was done in department of pathology with attached tertiary care hospital.

\section{INCLUSION CRITERIA: -}

All the patients, having serologically confirmed dengue (NS1 antigen, IgG or IgM) fever patients above the age of 18 years admitted in our hospital. these cases.

Informed consent was taken from

\section{EXCLUSION CRITERIA:-}

1) Patients with history of known other haematological disorder.

2) Patients with concomitant infection.

3) Patients below the age of 18 years.
A detailed history of patient was taken which includes patient's age, sex, complaints, clinical presentation and laboratory investigations were recorded in all cases. $\mathrm{Hb}$ estimation, cell counts for example RBC and WBC, PCV, platelet and platelet indices were recorded on 3 part automated hematology analyzer (NIHON KOHDEN).

\section{OBSERVATION AND RESULTS}

All the patients were above the age of 18 years old irrespective of sex, having fever and serologically positive dengue fever were included in this study.

Table-1 : Age distribution of all cases.
\begin{tabular}{|l|l|l|}
\hline Age (Years) & No. of cases & $\%$ \\
\hline $18-30$ & 104 & $49.5 \%$ \\
\hline $31-40$ & 30 & $14.2 \%$ \\
\hline $41-50$ & 34 & $16.1 \%$ \\
\hline $51-60$ & 22 & $10.4 \%$ \\
\hline$>61$ & 20 & $9.5 \%$ \\
\hline Total & 210 & $100 \%$ \\
\hline
\end{tabular}

Youngest patient was 18 years old and oldest was 78 years old in the present study. 104 cases $(49.5 \%)$ were in the 2 nd decade of life, which was the most common age group. Mean age of presentation was 34 years old.

There were $115(54.7 \%)$ males and 95 (45.2\%) females; with slight male preponderance with $\mathrm{M}: \mathrm{F}$ ratio of 1.2:1.

Table-4: Distribution of clinical features

\begin{tabular}{|l|l|l|}
\hline Symptoms & No. of cases & Percentage \\
\hline Fever & 185 & $88 \%$ \\
\hline Bodyache & 122 & $58 \%$ \\
\hline Headache & 106 & $50.4 \%$ \\
\hline Lethargy & 100 & $47.6 \%$ \\
\hline Retro orbital pain & 36 & $17.1 \%$ \\
\hline Rash & 26 & $12.3 \%$ \\
\hline Bleeding manifestation & 28 & $13.3 \%$ \\
\hline
\end{tabular}

The most common presenting complaint was fever (185 cases) followed by bodyache (122 cases) in maximum patients and least presenting complaint was rash (26 cases).

Table 5: Clinical spectrum of dengue positive cases.

\begin{tabular}{|l|l|l|}
\hline Diagnosis & Number & Distribution \\
\hline Dengue fever & 185 & $88 \%$ \\
\hline Dengue hemorrhagic fever & 23 & $10.9 \%$ \\
\hline Dengue shock syndrome & 2 & $0.9 \%$ \\
\hline Total & 210 & $100 \%$ \\
\hline
\end{tabular}


Majority of the cases (88\%) were having dengue fever (185 cases). While 23 cases $(10.9 \%)$ had dengue hemorrhagic fever and 2 cases $(0.9 \%)$ were of dengue shock syndrome.

Table-7: Distribution of cases on the basis of hemoglobin and hematocrit level
\begin{tabular}{|l|l|l|l|l|l|}
\hline Hemoglobin level & Hematocrit \\
\hline Hb (gm/dl) & No. of cases & $\%$ & HCT $(\%)$ & No. of cases & $\%$ \\
\hline $6.4-9$ & 19 & $9.0 \%$ & $19-29$ & 19 & $9.0 \%$ \\
\hline $9.1-12$ & 66 & $31.4 \%$ & $30-39$ & 66 & $31.4 \%$ \\
\hline $12.1-15$ & 98 & $46.6 \%$ & $40-49$ & 98 & $46.6 \%$ \\
\hline $15.1-18$ & 27 & $12.8 \%$ & $50-59$ & 27 & $12.8 \%$ \\
\hline Total & 210 & $100 \%$ & Total & 210 & $100 \%$ \\
\hline
\end{tabular}

Most of the patients i.e. 98 cases $(46.6 \%)$ were noted with hemoglobin ranging from $12-15 \mathrm{gm} / \mathrm{dl}$ followed by 66 cases $(31.4 \%) \mathrm{Hb}$ ranging from $9-12 \mathrm{gm} / \mathrm{dl}$. Least cases i.e. $19(9 \%)$ showed $\mathrm{Hb}$ ranging from $6.4-9 \mathrm{gm} / \mathrm{dl}$.

Maximum patients i.e. 98 cases $(46.6 \%)$ were noted with hematocrit levels ranging from $40-49 \%$, followed by 66 cases (31.4\%) PCT ranging from $30-39 \%$. Least cases i.e. $19(9 \%)$ showed PCT ranging from $19-29 \%$.
Table-8: Distribution of cases on the basis of total leucocyte count

\begin{tabular}{|l|l|l|}
\hline TLC $\left(\right.$ cell $\left./ \mathbf{m m}^{\mathbf{3}}\right)$ & No. of cases & \% \\
\hline$<4000$ & 72 & $34.2 \%$ \\
\hline $4000-11000$ & 128 & $60.9 \%$ \\
\hline$>11000$ & 10 & $4.7 \%$ \\
\hline Total & 210 & $100 \%$ \\
\hline
\end{tabular}

Maximum number of patients i.e. 128 cases $(60.9 \%)$ had TLC within normal limit, followed by 72 cases (34.2\%) having leucopenia and minimum were 10 cases (4.7 $\%$ ) having leucocytosis.

Table-9: Differential WBC count pattern

\begin{tabular}{|l|l|l|l|}
\hline Differential count pattern & Leucopenia & Normal WBC count & Leucocytosis \\
\hline Lymphocytosis & $29 / 72(40.2 \%)$ & $59 / 128(46 \%)$ & $3 / 10(30 \%)$ \\
\hline Neutrophilia & $15 / 72(20.8 \%)$ & $23 / 128(17.9 \%)$ & $4 / 10(40 \%)$ \\
\hline Within normal limit & $28 / 72(38.8 \%)$ & $46 / 128(35.9 \%)$ & $3 / 10(30 \%)$ \\
\hline
\end{tabular}

Table-12: Distribution of cases on the basis of platelet count

\begin{tabular}{|l|l|l|}
\hline Platelet $\left(\mathbf{c e l l s} / \mathbf{m m}^{\mathbf{3}}\right)$ & No. of cases & \% \\
\hline$<20,000$ & 7 & $3.3 \%$ \\
\hline $20,000-60,000$ & 87 & $41.4 \%$ \\
\hline $61,000-1.5$ lakh & 81 & $38.5 \%$ \\
\hline$>1.5$ lakh & 35 & $16.6 \%$ \\
\hline Total & 210 & $100 \%$ \\
\hline
\end{tabular}

Maximum number of patients i.e. 87 cases $(41.4 \%)$ had platelet count with moderate thrombocytopenia, followed by 81 cases $\quad(38.5 \%)$ having mild thrombocytopenia and minimum cases were seen ( 7 cases i.e. 3.3\%) having severe thrombocytopenia.

Table- 13: Distribution of cases of thrombocytopenia on the basis of severity of disease

\begin{tabular}{|l|l|l|l|}
\hline Thrombocytopenia & Dengue fever & DHF and DSS & Total \\
\hline Mild & $81(54 \%)$ & $0(0 \%)$ & 81 \\
\hline Moderate & $69(46 \%)$ & $18(72 \%)$ & 87 \\
\hline Severe & $0(0 \%)$ & $7(28 \%)$ & 7 \\
\hline Total & $150 / 175$ & $25 / 175$ & 175 \\
\hline
\end{tabular}

Table-14: Distribution of cases of thrombocytopenia on the basis bleeding manifestations.

\begin{tabular}{|c|c|c|c|c|c|c|c|}
\hline \multirow[b]{2}{*}{ Bleeding manifestation } & \multicolumn{6}{|c|}{ Platelet count (per cu.mm) } & \multirow[t]{2}{*}{ Total } \\
\hline & $\leq \mathbf{2 0 , 0 0 0}$ & 21-30,000 & $31-40,000$ & $41-50,000$ & 51-1 lac & $>1$ lac & \\
\hline Petechiae & 5 & 7 & 6 & 0 & 0 & 0 & 18 \\
\hline Hematemesis & 4 & 2 & 2 & 0 & 0 & 0 & 8 \\
\hline Melena & 2 & 1 & 0 & 0 & 0 & 0 & 3 \\
\hline Total number with platelet count, n (\%) & $11(37.9)$ & $10(34.4)$ & $8(27.5)$ & 0 & 0 & 0 & 29 \\
\hline
\end{tabular}

Table- 16: Mean Platelet Volume (MPV), Plateletcrit (PCT) and Platelet Distribution Width (PDW) in Thrombocytopenic and Non Thrombocytopenic Patients (categorization based on analyser)

\begin{tabular}{|l|l|l|l|l|l|l|}
\hline Category & $\begin{array}{l}\text { No. of } \\
\text { patients }\end{array}$ & Percentage & $\begin{array}{l}\text { Mean platelet } \\
\text { count } \\
(\mathbf{x ~ 1 0} / \mathbf{L})\end{array}$ & $\begin{array}{l}\text { Mean platelet } \\
\text { volume } \\
(\mathbf{f L})\end{array}$ & $\begin{array}{l}\text { Plateletcrit } \\
(\boldsymbol{\%})\end{array}$ & $\begin{array}{l}\text { Platelet } \\
\text { distribution width }\end{array}$ \\
\hline $\begin{array}{l}\text { Thrombocytopenic } \\
(<\mathbf{1 5 0} \mathbf{1 0} / \mathbf{L})\end{array}$ & 175 & $83.3 \%$ & $\begin{array}{l}72.35 \\
( \pm 39.03)\end{array}$ & $\begin{array}{l}9.29 \\
( \pm 1.58)\end{array}$ & $\begin{array}{l}0.05 \\
( \pm 0.03)\end{array}$ & $\begin{array}{l}17.81 \\
( \pm 1.47)\end{array}$ \\
\hline $\begin{array}{l}\text { Non } \mathbf{m} \text { thrombocytopenic } \\
(>\mathbf{1 5 0} \mathbf{1 0} / \mathbf{L})\end{array}$ & 35 & $16.6 \%$ & 251.11 & 7.55 & 0.18 & 16.67 \\
$( \pm 0.09)$ & $( \pm 1.16)$ \\
\hline P value & & $( \pm 94.59)$ & $( \pm 1.43)$ & 0.103 & $<0.0001$ & 0.1010 \\
\hline
\end{tabular}


The mean MPV in thrombocytopenic patients [9.29( \pm 1.58$)]$ was found to be significantly higher than in non-thrombocytopenic patients.

The mean PDW in thrombocytopenic patients $[17.81( \pm 1.47)]$ was also found to be significantly higher than in non thrombocytic patients.

Thrombocytopenia patients revealed statistically significant high MPV and PDW and low plateletcrit.

\section{DISCUSSION}

The study of hematological profile of seropositive (IgM, IgG and NS1 antigen) dengue fever patients was done in department of pathology in our institute which is a tertiary care centre.

Most $(49.5 \%)$ patients in our study were in the $2^{\text {nd }}$ decade of life with M:F ratio of 1.2:1. A similar finding was observed by Shamsunder Khatroth ${ }^{(9)}$, Kailash C. Meena et al. ${ }^{(5)}$ and Yashaswini LS et al ${ }^{(10)}$.

Fever was the most common symptom noted in dengue patients. Followed by bodyache and lethargy and least cases were having rash. Similar findings were observed in the studies done by other authors. ${ }^{(12,13,14,10)}$

Dengue fever was common clinical spectrum observed in present study. Similar findings were noted by other authors. ${ }^{(5,14)}$

In our study for serology pattern in dengue patients, $122(58 \%)$ cases were having IgM pattern followed by IgM + NS1 antigen pattern. Least i.e. 11 (5.2\%) cases were having $\operatorname{IgM}+\operatorname{IgG}$ pattern. However Kunal Tewari et al ${ }^{(15)}$ study, IgM+ IgG had maximum number of cases.NS1 antigen pattern was most commonly noted by Joshi AA et $\mathrm{al}^{(11)}$.

In present study maximum patients had hemoglobin levels ranging between 9.1 $-15 \mathrm{gm} / \mathrm{dl}$ with hematocrit levels ranging between $30-49 \%$. Similar findings were also noted by Shamsunder Khatroth ${ }^{(9)}$ and Kailash C Meena et $\mathrm{al}^{(5)}$.

In our study maximum dengue patients were having leucocyte count ranging from $4000-11000 /$ cumm.
However, counts were on the lower side of the normal limit.

Similarly, Shamsunder Khatroth, Ferede et al, Priya and Bindu M also noted maximum cases in leucocyte count ranging within normal limit. However, Kailash C. Meena et al, Yashaswini L S et al and Joshi AA et al showed maximum patients in leucopenia range. $(9,13,12,5,10,11)$

In our study, maximum patients $(83.2 \%)$ had thrombocytopenia. Among thrombocytopenic patients $41.4 \%$ cases had moderate thrombocytopenia ranging 20,000 - 60,000/cumm and $3.3 \%$ cases were having severe thrombocytopenia $(<20,000 /$ cumm). Kailash C. Meena et al, Ferede et al, Tahlan A et al and Shamsunder Khatroth had similar findings. $(5,13,12,9)$

Bleeding manifestation was noted in 29 patients. Amongst which petechiae was noted in 18 cases, hematemesis in 8 patients and melena was noted in 3 cases. Kunal Tewari et al ${ }^{(15)}$ and Yashaswini LS et al ${ }^{(10)}$ had same observation.

In our study mean platelet count, mean platelet volume and platelet distribution width showed highly significantly increase in the values for thrombocytopenic dengue patients than nonthrombocytopenic dengue patients. Aashna et $\mathrm{al}^{(16)}$ had similar findings of platelet indices according to thrombocytopenia.

\section{CONCLUSION}

Hematocrit (HCT) monitoring is useful to evaluate the degree of plasma leakage and to determine therapeutic intervention in case of dengue fever. Platelet count and platelet indices play significant role in predicting severity of outcome of dengue fever.

\section{Acknowledgement: None}

Conflict of Interest: None

Source of Funding: None

Ethical Approval: Approved 


\section{REFERENCES}

1. Guha-Sapir D, Schimmer B. Dengue fever: new paradigms for a changing epidemiology. Emerg Themes Epidemiol. 2005;2(1):1-10.

2. Park K. Epidemiology of Communicable Diseases: Dengue syndrome. In: Park's textbook of Preventive and Social Medicine. 20th ed. Jabalpur, India: M/s Bhanarsidas Bhanot. 2009:218-22.

3. De Paula SO, Fonseca BA. Dengue: A review of the laboratory tests a clinician must know to achieve a correct diagnosis. Braz J Infect Dis. 2004;8(6):390-8.

4. Srichaikul T, Nimmannita S. Haematology in dengue and dengue haemorrhagic. Baillieres Best Pract Res Clin Haematol. 2000;13 (2):261-76.

5. Meena KC, Jelia S, Meena S, Arif $M$, Ajmera D, Jatav VS. A study of hematological profile in dengue fever at tertiary care center, Kota Rajasthan, India. Int J Adv Med 2016;3:621-4

6. Ministry of Health Sri Lanka. Guidelines on Management of Dengue Fever \& Dengue Haemorrhagic Fever in Children and Adolescents. 2012; 1-2.

7. Kao CL, King CC, Chao DY, Wu HL, Chang GJ. Laboratory diagnosis of dengue virus infection: current and future perspectives in clinical diagnosis and public health. J Mibrobiol Immunol Infect. 2005;38(1):5-16.

8. Ageep AK, Malik AA, Elkarsani MS. Clinical presentations and laboratory findings in suspected cases of dengue virus. Saudi Med J. 2006;27(11):1711-3.

9. Shamsunder Khatroth. A Study on Clinical and Hematological Profile of Dengue Fever in a Tertiary Care Hospital. IAIM, 2017; 4(8): 96-102.

10. Yashaswini LS, Priya. Vidyashri. A study of hematological parameters and requirement of platelet transfusion in dengue fever. Int $\mathbf{J}$ Adv Med 2017;4:1668-71.

11. Joshi AA, Gayathri BR, Gowda YR. The total leucocyte count-its utility in dengue. Int J Adv Med 2017;4:1621-6.

12. Tahlan A, Bhattacharya A, Singla N, Singh R. Haematological profile of dengue fever. Int J Res Med Sci 2017;5:5367-71.

13. Ferede, G., Tiruneh, M., Abate, E. et al. A study of clinical, hematological, and biochemical profiles of patients with dengue viral infections in Northwest Ethiopia: implications for patient management. BMC Infect Dis 2018, $616: 1-6$.

14. Priya AV, Bindu M H. Clinico Hematological profile of dengue in children in a tertiary care hospital. IP Int $\mathrm{J}$ Med Paediatr Oncol 2020;6(4):147-151.

15. Tewari K., Tewari V.V., Mehta R. Clinical and hematological profile of patients with dengue fever at a tertiary care hospital - an observational study. Mediterr J Hematol Infect Dis 2018, 10(1):1-7

16. Aashna, Mahajan D, Koul K K, Jandial A, Platelet count correlation: automated versus manual on peripheral smear. Indian J Pathol Oncol 2019;6(3):381-387

How to cite this article: Karmakar S, Patil N. A study of hematological profile in dengue fever in a tertiary care hospital. Int $J$ Health Sci Res. 2022; 12(3): 18-22. DOI: https://doi.org/ 10.52403/ijhsr.20220303 